\title{
Influence of fiber posts on the fracture resistance of endodontically treated premolars with different dental defects
}

\author{
Qian-Qian Hou ${ }^{1}$, Yi-Ming Gao ${ }^{2}$ and Lei Sun ${ }^{2}$
}

This study aimed to evaluate the influence of quartz fiber post placement on the fracture resistance of endodontically treated premolars with different dental defects under dynamic loading. Fifty extracted single-rooted mandibular premolars were randomized into five groups. Each group was prepared according to numbers of residual walls ranged from 0 to 4 . Then each group was divided into two subgroups with one restored with quartz fiber posts and the other without posts. In no-post groups, gutta percha point 2 mm below cemento-enamel junction was removed. Composite resin was adapted to the well and used to shape the core directly. Each tooth was restored with a complete metal crown. Dynamic loading was carried out in a masticatory simulator with a nominal load of $50 \mathrm{~N}$ at $2 \mathrm{~Hz}$ for 300000 loading cycles. Then a quasi-statically load was applied in a universal testing machine $30^{\circ}$ to the long axis with a crosshead speed of $1 \mathrm{~mm} \cdot \mathrm{min}^{-1}$ until fracture. Data were analyzed with one-way analysis of variance and pairwise comparison $(\boldsymbol{P}<0.05)$. No specimens failed during dynamic loading. The fracture resistance enhanced with the increase of numbers of coronal walls and the differences were significant $(\boldsymbol{P}<0.05)$. Placement of fiber posts had a significant effect when fewer than two walls remained $(\boldsymbol{P}<0.05)$, but it had no significant influence in groups with two, three or four walls $(\boldsymbol{P}>0.05)$. Fiber post did not change failure mode, and the fracture pattern was mainly favorable. More dentin walls need to be retained in clinic. When no less than two walls remained, a fiber post is not always necessary.

International Journal of Oral Science (2013) 5, 167-171; doi:10.1038/ijos.2013.52; published online 2 August 2013

Keywords: dynamic loading; fiber post; fracture resistance; residual wall

\section{INTRODUCTION}

The post-core and crown restoration is a common prosthodontic method to preserve residual roots and crowns. Recently, fiber posts have become more and more popular because they have a modulus of elasticity similar to dentin, high tensile strength, good transparency and could be removed easily. ${ }^{1}$ However, not all endodontically treated teeth need post restoration. Naumann et al. ${ }^{2}$ figured that the fracture resistance mainly depended on the preservation of residual dentin. While during post space preparation some root dentin was removed, which could increase the risk of root fracture. Up to now, no clear guideline has been proposed on whether a post should be applied to teeth with different dental defects, so objective data on fracture resistance when applying fiber posts to teeth with different amounts of residual tooth structure need to be obtained.

Different factors may result in various types of dental defect clinically. Since mandibular premolars mainly suffer proximal caries and buccal wedge-shaped defect, which could lead to mesial, distal and buccal dental defect, this experiment simulated common dental defect situations of mandibular premolars in clinic.

The aim of this study was to evaluate the influence of quartz fiber post placement on the fracture resistance and failure patterns of endodontically treated premolars with different dental defects under dynamic loading. ${ }^{3}$ The null hypothesis of this experiment was that neither the presence of fiber post nor residual coronal walls would affect the fracture resistance of premolars.

\section{MATERIALS AND METHODS}

Teeth selection

Fifty human mandibular premolars extracted for orthodontic reasons were obtained from the Oral and Maxillofacial Surgery Department of Hospitals Affiliated to Shanghai Jiao Tong University. All teeth were examined through a magnifying glass ${ }^{4}$ to ensure that there were no caries, cracks, previous restorations, internal root resorption or obstructions within the canal. Dental plaque, calculus and periodontal tissues were removed. Teeth were stored in $0.9 \%$ saline solution during all subsequent procedures. ${ }^{5}$

\section{Root canal treatment}

The pulp chamber of each tooth was opened using fissure bur (SS White, Lakewood, NJ, USA), and the root canal was instrumented using 0.02 tapered hand files (K-files; Dentsply-Maillefer, Ballaigues, Switzerland) to International Standardization Organization (ISO) size

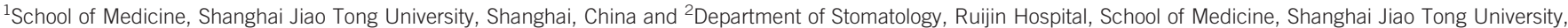
Shanghai, China

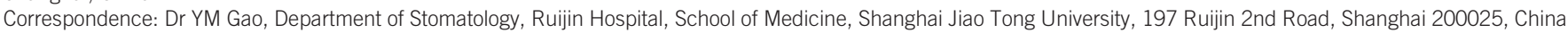
E-mail: drgaoym@163.com

Received 29 December 2012; accepted 26 June 2013 
40 at $0.5 \mathrm{~mm}$ above the apex with routine preparation technique. The coronal root canal was not flared using Pro-Files in order to preserve tooth structure. Three percent hydrogen peroxide was used to irrigate root canals between instrumentation. All teeth were obturated with gutta-percha points (Dentsply-Maillefer, Ballaigues, Switzerland) and endodontic sealer (Zinc oxide eugenol paste; Dentsply-Maillefer, Ballaigues, Switzerland) using the lateral condensation technique.

\section{Specimen grouping and preparation}

Root length and the buccolingual and mesiodistal width at the cemento-enamel junction (CEJ) level were measured by a digital caliper (Measuring Tool Enterprise, Shanghai, China) accurate to $0.02 \mathrm{~mm}$. All teeth were randomly divided into five groups (A-E) of 10 teeth each. Analysis of variance was used to determine the significant difference among the groups $(P>0.05)$. Each group was prepared according to numbers of residual coronal walls (Figure 1). Excess walls were removed using a diamond bur (TF-11; ISO 179/014; MANI, Tochigi, Japan). ${ }^{6}$ The specimens were prepared as follows:

Group A: teeth not containing any coronal walls, but with a $0.5-\mathrm{mm}$ ferrule $;^{7}$

Group B: teeth containing one coronal wall (lingual), with the other walls eliminated to $0.5 \mathrm{~mm}$ above the CEJ;

Group C: teeth containing two residual coronal walls (facial and lingual), with mesial and distal walls removed to $0.5 \mathrm{~mm}$ above the CEJ;

Group D: teeth containing three coronal dentin walls (facial, lingual and mesial), with the distal wall removed to $0.5 \mathrm{~mm}$ above the CEJ;

Group E (control group): teeth containing four walls (facial, lingual, mesial and distal), without coronal walls eliminated.

Groups A-E were divided into two subgroups of five teeth each, designated with the subscripts 0 and 1 . In subgroups $A_{0}$ to $E_{0}$, gutta percha point $2 \mathrm{~mm}$ below the CEJ was removed, then light-cured composite resin (Filtek Z350; 3M ESPE, Sao Paulo, MN, USA) was used to shape the core layer by layer. For subgroups $A_{1}$ to $E_{1}$, post space was prepared with the Pre-Shaping drills (D.T. Light-Post Double Taper; Bisco Inc., Schaumburg, IL, USA) and finally shaped with 2\# Finishing drills (D.T. Light-Post Double Taper; Bisco Inc., Schaumburg, IL, USA) to achieve a post length of $8 \mathrm{~mm},{ }^{8}$ ensuring at least $4 \mathrm{~mm}$ gutta percha seal apically. Self-etching bonding agent (Self-etch; Bisco Inc., Schaumburg, IL, USA) and prefabricated quartz fiber posts (D.T. Light-Post; Bisco Inc., Schaumburg, IL, USA) were introduced into the prepared canal space one after another. Excess luting agent was removed and a LED light-curing unit (Elipar FreeLight 2, $800 \mathrm{~mW} \cdot \mathrm{cm}^{-2}$ light output; $3 \mathrm{M}$ ESPS, Sao Paulo, MN, USA) was placed directly on the post for $40 \mathrm{~s}$. The bonding agent (SelfEtch Adhesive; 3M ESPS, Sao Paulo, MN, USA) was placed on the exposed coronal tooth structure and the post, which was then light polymerized for $20 \mathrm{~s}$. Composite resin core was fabricated layer by layer and light polymerized for $40 \mathrm{~s}$ with $2 \mathrm{~mm}$ of resin increment each. After complete polymerization of the resin, all teeth were prepared

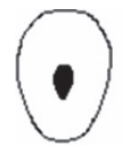

A

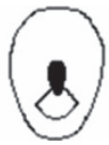

B

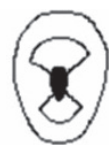

C

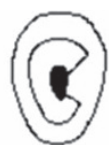

D

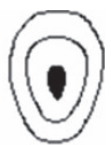

E
Figure 1 Specimens design. Coronal view of the location of remaining coronal dentin walls and the root canal. to the standardized dimensions with a height of $6 \mathrm{~mm}$ and a total convergence angle of approximately $5.0^{\circ}$. The thickness of residual coronal dentin walls after crown preparation was about $1 \mathrm{~mm}$.

\section{Full crown restoration}

After tooth preparation, the crown parts of each tooth were coated with a $20 \mu \mathrm{m}$ thick layer of lubricant (Jingliu, Tokyo, Japan). Then wax patterns were formed directly on tooth specimens using a polysiloxane (Heraeus, Hanau, Germany) mold of the first mandibular premolar. Wax patterns were invested with gypsum investment and cast with $\mathrm{Ni}-$ $\mathrm{Cr}$ alloy by the same technician. Cast crowns were adjusted until they were fully seated and air-abraded with $50 \mu \mathrm{m}$ alumina under $0.2 \mathrm{MPa}$ pressure. All crowns were cemented with glass ionomer cement (GC Fuji I Co., Ltd., Tokyo, Japan) under finger pressure for $5 \mathrm{~min}$, and excess adhesive was removed after the final setting of the luting agent.

\section{Specimen embedding}

All specimens were embedded $2 \mathrm{~mm}$ below the CEJ in autopolymerizing acrylic resin contained in custom-made molds, orienting the long axes of all teeth perpendicular to the horizontal plane. ${ }^{9}$ Polysiloxane impression material (Flexitime; Heraeus Kulzer, Hanau, Germany) ${ }^{10}$ was applied in the root region with an average thickness of $0.25 \mathrm{~mm}$ to simulate the periodontal ligament. Specimens were stored in saline solution for 1 week at room temperature before testing.

\section{Dynamic loading}

In order to simulate the occlusal situation in clinic, dynamic loading was carried out in a masticatory simulator (JWD Motor Co., Ltd., Chengdu, China, supplied by West China School of Stomatology) with a nominal load of $50 \mathrm{~N}$ at $2 \mathrm{~Hz}$ for 300000 loading cycles, orienting the loading site perpendicular to the occlusal surface and keeping all specimens in wet environment during the whole process.

\section{Fracture resistance test}

After dynamic loading, all specimens were then quasi-statically loaded in a universal testing machine (AG-IS; Shimadzu, Kyoto, Japan) at a $30^{\circ}$ angle to the longitudinal axis of the tooth with a crosshead speed of $1 \mathrm{~mm} \cdot \mathrm{min}^{-1}$ until fracture. ${ }^{11}$ The loading site was at the central fissure of the occlusal surface pointing down to the lingual incline of the buccal cusp. Force data applied over time were recorded in a computer connected to the loading machine. The fracture of specimens under compressive loading was determined when the force-versus-time graph showed an evident load drop. Both the failure load and failure mode were recorded.

\section{Statistical analysis}

Data were statistically analyzed with SPSS 17.0 (SPSS Inc., Chicago, IL, USA). One-way analysis of variance was used to reveal difference in failure load among groups with various coronal walls; pairwise comparison was used to detect significant differences between groups with and without a post; failure mode was analyzed by Fisher's exact test; $P$ was set to 0.05 for all statistical tests.

\section{RESULTS}

No specimens failed during dynamic loading. The mean failure loads were listed in Table 1 and graphically represented in Figure 2. The fracture resistance enhanced with the increase of the number of coronal walls and the difference was significant $(P<0.05)$. Pairwise comparison indicated that the placement of fiber post had a significant influence on the mean failure load in groups with zero or one coronal 


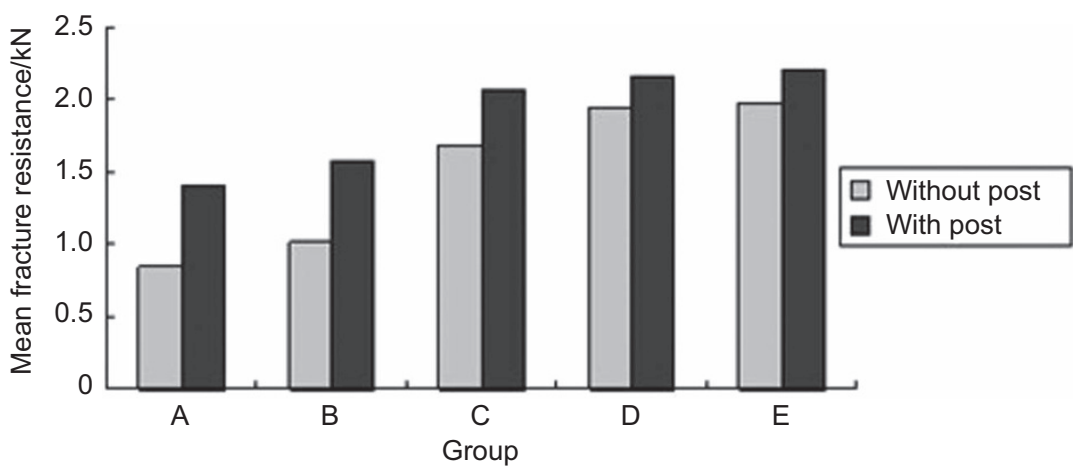

Figure 2 Mean fracture resistance of endodontically treated premolars with or without post according to groups with different numbers of coronal walls.

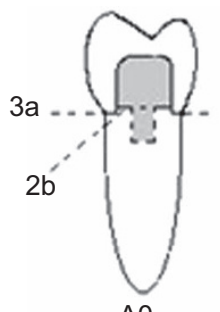

A0

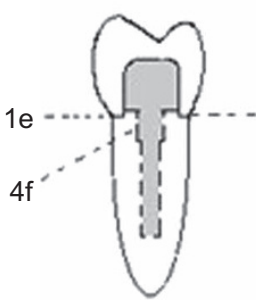

A1

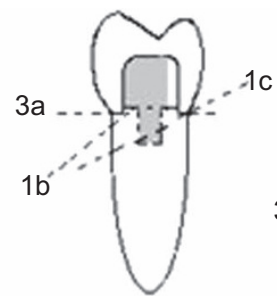

B0

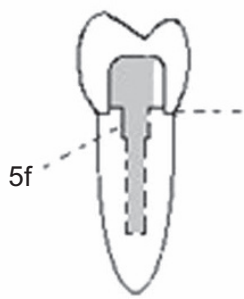

B1

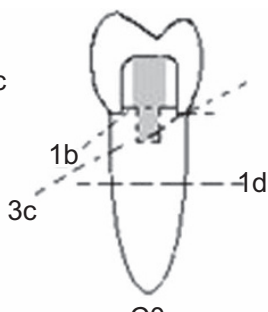

$\mathrm{CO}$

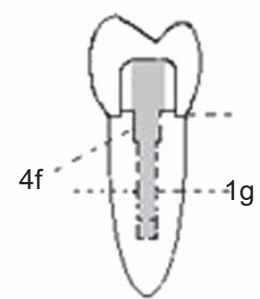

C1

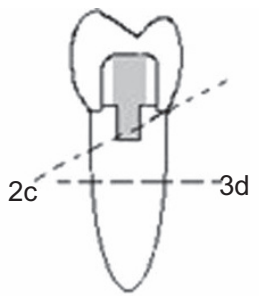

D0

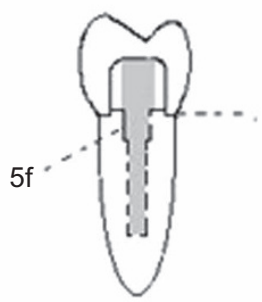

D1

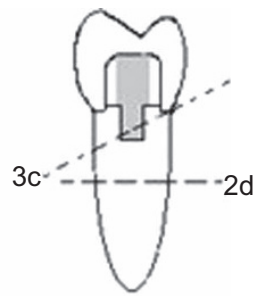

E0

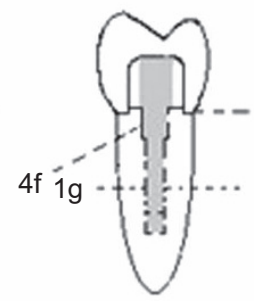

E1

Figure 3 Failure mode and frequency (number) of groups.

wall ( $P=0.017$ and $P=0.000$, respectively), but it had no significant influence in groups with two, three or four walls $(P=0.148, P=0.390$ and $P=0.367$, respectively).

The failure mode and the frequency were displayed in Table 2 and illustrated in Figure 3. Fisher exact test showed the placement of fiber posts had no significant statistical difference on failure mode $(P>0.05)$, and the fracture pattern was mainly favorable.

Table 1 Fracture loads in $\mathrm{kN}$ (means \pm standard deviations, $n=5$ )

\begin{tabular}{lccc}
\hline Groups & Coronal walls & Without post $\left(A_{0}-E_{0}\right)$ & With post $\left(A_{1}-E_{1}\right)$ \\
\hline A & 0 & $0.85 \pm 0.12$ & $1.41 \pm 0.36$ \\
$B$ & 1 & $1.02 \pm 0.17$ & $1.58 \pm 0.18$ \\
C & 2 & $1.68 \pm 0.22$ & $2.07 \pm 0.39$ \\
D & 3 & $1.94 \pm 0.45$ & $2.16 \pm 0.37$ \\
E & 4 & $1.98 \pm 0.30$ & $2.21 \pm 0.43$ \\
\hline
\end{tabular}

Table 2 Molds of failure

\begin{tabular}{|c|c|c|c|c|c|c|c|c|c|c|}
\hline \multirow{2}{*}{$\begin{array}{l}\text { Molds of } \\
\text { failure }\end{array}$} & \multicolumn{2}{|c|}{$\begin{array}{c}\text { A } \\
(0 \text { wall) }\end{array}$} & \multicolumn{2}{|c|}{$\begin{array}{c}\text { B } \\
\text { (1 wall) }\end{array}$} & \multicolumn{2}{|c|}{$\begin{array}{c}\text { C } \\
\text { (2 walls) }\end{array}$} & \multicolumn{2}{|c|}{$\begin{array}{c}\text { D } \\
\text { (3 walls) }\end{array}$} & \multicolumn{2}{|c|}{$\begin{array}{c}E \\
\text { (4 walls) }\end{array}$} \\
\hline & $A_{0}$ & $A_{1}$ & $\mathrm{~B}_{0}$ & $\mathrm{~B}_{1}$ & $\mathrm{C}_{0}$ & $\mathrm{C}_{1}$ & $\mathrm{D}_{0}$ & $\mathrm{D}_{1}$ & $\mathrm{E}_{0}$ & $\mathrm{E}_{1}$ \\
\hline Favorable & 5 & 5 & 5 & 5 & 4 & 4 & 2 & 5 & 3 & 4 \\
\hline Unfavorable & 0 & 0 & 0 & 0 & 1 & 1 & 3 & 0 & 2 & 1 \\
\hline
\end{tabular}

Restorable failure mode contained $\mathrm{a}, \mathrm{b}, \mathrm{c}$, e and $\mathrm{f}$. Unrestorable failure mode contained $d$ and $g$. The fracture lines of $a, b$ and $c$ were within cervical third. Modes e and f consisted of cervical third fracture and post debonding. The fracture line of $\mathrm{d}$ was in middle third. Mode $\mathrm{g}$ consisted of middle third fracture and post fracture.

\section{DISCUSSION}

This study was designed to evaluate the fracture resistance and failure patterns of mandibular premolars with different numbers of residual walls and restored with or without quartz fiber posts. The null hypothesis was rejected since the fracture resistance showed significant differences in terms of the number of residual walls and the placement of fiber posts.

One limitation of many previous fatigue studies is using static single load, ${ }^{12-13}$ which presents only a partial indication as to what can actually occur in the mouth. In order to simulate the actual clinical condition and acquire meaningful results, this study adopted dynamic loading and fatigue test that carried on a masticatory simulator. Since the daily chewing force of average people is $30-300 \mathrm{~N}$, and the force of mandibular premolars is a little small, a load of $50 \mathrm{~N}$ was chosen as the repeated loading force. Recently, similar dynamic loading force has been used in vitro studies frequently. ${ }^{14-15}$ 
Ferrule effect has received much attention on post crown restoration lately. Some scholars believed that the ferrule with no less than $2 \mathrm{~mm}$ could enhance the fracture resistance obviously. ${ }^{16}$ However, a circumferential ideal ferrule with the same height is hard to achieve without gingivectomy, prolongation of dental crown or orthodontic traction in clinic. Therefore, a ferrule of $0.5 \mathrm{~mm}$ was chosen for Group A to imitate unfavorable clinical condition, and this ferrule design was the same as Mangold and Kern's study. ${ }^{7}$

Soares et al. ${ }^{17}$ figured that the periodontal simulation could influence fracture behavior and modify failure mode in fracture testing. In order to simulate practical conditions in clinic, this study took this into consideration by adding a layer of polysiloxane impression material to imitate periodontium.

This study indicated that the fracture resistance of all groups restored with fiber posts was higher than groups without posts. Pairwise comparison showed the placement of a fiber post had a significant influence in groups with 0 or 1 coronal wall. When an endodontically treated tooth was restored with a post, the post could redistribute the stress to increase the fracture resistance. ${ }^{18}$ Nam et al.'s study ${ }^{19}$ demonstrated that in the zero-wall group without posts, stress was concentrated at the coronal and lingual area of CEJ, but no obvious stress concentration was found in that with posts. This result supports the current study. Mangold and Kern's study ${ }^{7}$ indicated that placement of a glass-fiber post had a significant influence on the fracture resistance when fewer than two cavity walls remained, which agrees with this study.

To the contrary, the post effect was not significant in groups with two, three or four walls, on condition that the thickness of dentin walls after tooth preparation was $1 \mathrm{~mm}$, and there were facial and lingual walls in two-wall group. In this study, gutta percha point $2 \mathrm{~mm}$ below CEJ was removed in the no-post group. It seemed like composite resin core fabrication with a 2-m -well in the root canal could not only enhance retention but also protect adequately against root fracture. In addition, with the increase of coronal walls, stress was distributed evenly in root dentin. ${ }^{19}$ A study ${ }^{20}$ on 6-year survival rate of premolars revealed that teeth with one, two and three coronal walls had significantly lower failure risks than those without coronal walls. These may explain why the post effect was not significant in groups with substantial coronal structure. So it can be concluded that not all endodontically treated teeth need post restoration and the number of residual dentin walls need to be considered.

Generally speaking, failure behavior contained restorable and unrestorable mode. ${ }^{21}$ Restorable failure mode composed of cervical root fracture and post failure. Otherwise, fracture line below cervical third of the root was considered as unrestorable failure behavior. In failure patterns, all specimens in zero-wall group and one-wall group presented restorable failure behavior, and with the increase of remaining walls, unrestorable failure mode appeared. When there was little coronal structure, stress was concentrated in tooth cervical, which induced restorable failure patterns. As the remaining walls increased, stress concentration transmitted from tooth cervical to apical, ${ }^{22}$ so the fracture line was possible to move down. Posts could be bonded to tooth structure with resin luting agents, and this allowed the formation of a single unit where tooth, post, core and crown may function as a cohesive unit; ${ }^{23}$ hence, stress was distributed and post groups mainly displayed restorable failure mode. Fiber posts have a modulus of elasticity similar to dentin, and the change of stress distribution in root dentin is small after fiber post restoration, which is possibly why fiber post did not alter failure mode.

Future research is necessary using a similar study design but subjecting the specimens to thermocycling to simulate oral environment.
Fiber posts could also be compared with other material posts, such as cast metal posts or all-ceramic posts, in order to distinguish differences under simulated clinical conditions.

\section{CONCLUSIONS}

With the limitations of this in vitro study, the following conclusions were drawn:

(i) The fracture resistance was enhanced with the increase of the number of coronal walls.

(ii) Placement of fiber posts had a significant effect on the mean fracture resistance of endodontically treated premolars when fewer than two coronal walls remained, but no significant influence appeared in groups with two, three or four walls, on condition that the thickness of dentin walls after tooth preparation was $1 \mathrm{~mm}$, and there were facial and lingual walls in two-wall group.

(iii) Fiber post did not change failure mode, and the fracture pattern was mainly favorable.

\section{ACKNOWLEDGEMENTS}

The research was granted by Shanghai Health Bureau (2010244). We thank West China School of Stomatology, Sichuan University for providing masticatory simulator and technical assistance. And we would like to thank all the staff in Department of Stomatology, Ruijin Hospital, Shanghai Jiao Tong University for their help and advice during this study.

1 Fredrisksson M, Astback J, Pamenius M et al. A retrospective study of 236 patients with teeth restored by carbon fiber-reinforced epoxy resin posts. J Prosthet Dent 1998 80(2): 151-157.

2 Naumann M, Preuss A, Rosentritt M. Effect of incomplete crown ferrules on load capacity of endodontically treated maxillary incisors restored with fiber posts, composite build-ups, and all-ceramic crowns: an in vitro evaluation after chewing simulation. Acta Odontol Scand 2006; 64(1): 31-36.

3 Sterzenbach G, Rosentritt M, Frankenberger R et al. Loading standardization of postendodontic restorations in vitro: impact of restorative stage, static loading, and dynamic loading. Oper Dent 2012; 37(1): 71-79.

4 Forberger N, Göhring TN. Influence of the type of post and core on in vitro marginal continuity, fracture resistance, and fracture mode of lithia disilicate-based allceramic crowns. J Prosthet Dent 2008; 100(4): 264-273.

5 Yilmaz $\mathrm{Y}$, Guler $\mathrm{C}$, Sahin $\mathrm{H}$ et al. Evaluation of tooth-fragment reattachment: a clinical and laboratory study. Dent Traumatol 2010; 26(4): 308-314.

6 Salameh Z, Sorrentino R, Papacchini F et al. Fracture resistance and failure patterns of endodontically treated mandibular molars restored using resin composite with or without translucent glass fiber posts. J Endod 2006; 32(8): 752-755.

7 Mangold JT, Kern M. Influence of glass-fiber posts on the fracture resistance and failure pattern of endodontically treated premolars with varying substance loss: an in vitro study. J Prosthet Dent 2011; 105(6): 387-393.

8 Giovani AR, Vansan LP, de Sousa Neto MD et al. In vitro fracture resistance of glassfiber and cast metal posts with different lengths. J Prosthet Dent 2009: 101(3): 183-188.

9 Cho H, Michalakis KX, Kim Y et al. Impact of interproximal groove placement and remaining coronal tooth structure on the fracture resistance of endodontically treated maxillary anterior teeth. J Prosthodont 2009; 18(1): 43-48.

10 Sterzenbach G, Kalberlah S, Beuer F et al. In-vitro simulation of tooth mobility for static and dynamic load tests: a pilot study. Acta Odontol Scand 2011; 69(5): 316-318.

11 Kivanç BH, Alaçam T, Görgül G. Fracture resistance of premolars with one remaining cavity wall restored using different techniques. Dent Mater J 2010; 29(3): 262-267.

12 Arunpraditkul S, Saenqsanon S, Pakviwat W. Fracture resistance of endodontically treated teeth: three walls versus four walls of remaining coronal tooth structure. Prosthodont 2009; 18(1): 49-53.

$13 \mathrm{Nq} \mathrm{CC}$, Dumbrique HB, Al-Bayat MI et al. Influence of remaining coronal tooth structure location on the fracture resistance of restored endodontically treated anterior teeth. J Prosthet Dent 2006; 95(4): 290-296.

14 Bergoli C, Amaral M, Baldissara P et al. Surviving of bovine teeth adhesively restored with 3 types of fiber post after fatigue resistance. Minerva Stomatol 2011; 60(6): 303-309. 
15 Krämer N, Rudolph H, Garcia-Godoy F et al. Effect of thermo-mechanical loading on marginal quality and wear of primary molar crowns. Eur Arch Paediatr Dent 2012; 13(4): 185-190.

16 Eraslan O, Aykent F, Yucel MT et al. The finite element analysis of the effect of ferrule height on stress distribution at post-and-core-restored all-ceramic anterior crowns. Clin Oral Investig 2009; 13(2): 223-227.

17 Soares CJ, Pizi EC, Fonseca RB et al. Influence of root embedment material and periodontal ligament simulation on fracture resistance tests. Braz Oral Res 2005; 19(1): 11-16.

18 Spazzin AO, Galafassi D, de Meira-Júnior AD et al. Influence of post and resin cement on stress distribution of maxillary central incisors restored with direct resin composite. Oper Dent 2009; 34(2): 223-229.

$19 \mathrm{Nam} \mathrm{SH}$, Chang HS, Min KS et al. Effect of the number of residual walls on fracture resistances, failure patterns, and photoelasticity of simulated premolars restored with or without fiber-reinforced composite posts. J Endod 2010; 36(2): 297-301.

20 Ferrari M, Vichi A, Fadda GM et al. A randomized controlled trial of endodontically treated and restored premolars. J Dent Res 2012; 91(7): 72-78.
21 Kumagae N, Komada W, Fukui $\mathrm{Y}$ et al. Influence of the flexural modulus of prefabricated and experimental posts on the fracture strength and failure mode of composite resin cores. Dent Mater J 2012; 31(1): 113-119.

22 Ichim I, Kuzmanovic DV, Love RM. A finite element analysis of ferrule design on restoration resistance and distribution of stress within a root. Int Endod J 2006; 39(6): 443-452.

23 Cormier CJ, Burns DR, Moon P. In vitro comparison of the fracture resistance and failure mode of fiber, ceramic, and conventional post systems at various stages of restoration. J Prosthodont 2001; 10(1): 26-36.

(c) This work is licensed under a Creative Commons Attribution-NonCommercial-NoDerivative Works 3.0 Unported License. To view a copy of this license, visit http:// creativecommons.org/licenses/by-nc-nd/3.0 